\title{
Perceived impacts of climate variability and change: an exploration of farmers' adaptation strategies in Zimbabwe's intensive farming region
}

\author{
Emmanuel Mavhura $(\mathbb{D} \cdot$ Tawanda Manyangadze $\cdot$ Komal Raj Aryal
}

Accepted: 8 June 2021 / Published online: 25 June 2021

(C) The Author(s) 2021

\begin{abstract}
Climate variability and change (CVC) affect many economic sectors including agriculture. In order to alleviate the negative impact of CVC on food production, farmers must adopt a range of strategies. However, the strategies will be less effective if farmers' perceptions on CVC are not considered. This study therefore, examined the perceptions of commercial farmers on CVC and their adaptation strategies to the perceived impacts. It used a crosssectional survey involving 365 farmers in the intensive farming region of Zimbabwe. Results showed that farmers' perceptions on increasing temperatures and decreasing rainfall amounts were cognate with climate data from the meteorological office. The findings also demonstrated that farmers were well aware of the CVC impacts on their livelihoods. These include increases in the frequency and severity of drought, and a shortening of the length of the rainy season.
\end{abstract}

E. Mavhura $(\bowtie) \cdot$ T. Manyangadze

Geography Department, Faculty of Science and

Engineering, Bindura University of Science Education,

Private Bag 1020, Bindura, Zimbabwe

e-mail: edmavhura@gmail.com; emavhura@buse.ac.zw

T. Manyangadze

School of Nursing and Public Health, Department of Public Health Medicine, University of KwaZulu-Natal, Durban, South Africa

K. R. Aryal

Faculty of Resilience, Rabdan Academy, Abu Dhabi, UAE
However, the most significant changes were observed among the natural and economic capitals including soil salinization, reduction in grazing pastures, fodder and crop yields in addition to increases in food prices. In response to the perceived impacts of local CVC, the farmers were adopting crop and land use management strategies that include planting rotation, cultivating short-season varieties and drought tolerant crops, crop and farm diversification, intensified irrigation, agroforestry, soil moisture conservation and mixed farming. The study concludes that farmers are active observers of local CVC. Therefore, they should modify their agricultural calendar and diversify their farming systems so as to better meet current and future risks from $\mathrm{CVC}$.

Keywords Adaptation - Climate change - Farmer . Perception $\cdot$ Strategies

\section{Introduction}

Climate variability and change (CVC) have been widely discussed across the globe (Elum et al., 2017). While climate change is about long-term changes (mostly in decades) in climatic patterns, climate variability is the short-term variations in weather elements observed in a specific place (Kolawole et al., 2016). The discussion of CVC has mainly focused on 
their mitigation and adaptation. Whereas climate mitigation is a proactive process that often entails reducing greenhouse gas emissions and improving earth's carbon sinks to limit global warming, adaptation is a reactive process of interventions that either manage the potential negative impacts or take advantage of opportunities emerging from a changing climate (Kelman et al., 2016). This study therefore, defines adaptation to CVC as the adjustments made within the natural and human systems in response to actual or expected climate and its effects in order to moderate harm or exploit beneficial opportunities (Pasimeni et al., 2019). Both mitigation and adaptation are long-term solutions that complement each other in minimising negative impacts of CVC. Although climate adaptation has been widely researched, it varies from place to place depending on the knowledge and perceptions of the farmers at risk. In addition, the increasing food security risk from CVC calls for more informed adaptation strategies in order to enhance food production (Jiri \& Mafongoya, 2018; Rojas-Downing et al., 2017). Both CVC mitigation and adaptation are greatly needed in the Global South, where communities largely depend on rainfed farming systems, which are highly sensitive to changes in climate (Mukwada \& Manatsa, 2013).

CVC affect agriculture, the environment and livelihoods, and exacerbate rural poverty (Ndamani $\&$ Watanabe, 2015). Research has shown that rural communities' vulnerability to CVC is strongly linked to their access to livelihood capitals (Masud et al., 2017). The rural livelihoods function as a system where each capital influences, and is influenced by another or other capitals (Mavhura, 2017). Their effect can be both positive and negative. Where access to livelihoods is improved, food production increases and poverty may decline (Kolawole et al., 2016). However, when the livelihood capitals are adversely affected, the capacities of farmers may become limited, leading to a cycle of vulnerability and poverty (Kangalawe et al., 2017). This is because farming largely depends on physical and natural capitals. Financial, human and social capitals also suffer losses when the natural and physical assets are affected negatively. In order to improve food sustenance in the face of CVC, farming communities need to develop context-specific adaptation measures. Therefore, an understanding of the farmers' perceptions of the changing climate can pave the way to understand adaptation strategies that may enhance food production.

Projections point to an increase in water stress and a reduction in food production in Africa, south of the Sahara where livelihoods of many people rely on agriculture (Pachauri et al., 2014). Zimbabwe is one of such countries with a highly variable climate which is manifested by frequent droughts and dry spells, occasional flood events and tropical cyclones (Government of Zimbabwe, 2017; Kusangaya et al., 2014). Since 1900 , the country has been experiencing a warming trend with minimum temperatures rising faster than maximum temperatures (Kusangaya et al., 2014). On average, the temperatures have been increasing by about $0.1{ }^{\circ} \mathrm{C}$ per decade (Government of Zimbabwe, 2016). The 1990 decade has been the warmest during the past century. The warming has been greatest during the dry season, while the wet season has recorded warmer day-time temperatures than night-time temperatures (Sango \& Nhamo, 2015). Likewise, the climatic period of 1982 to 2016 shows changes in intra-seasonal rainfall patterns in Zimbabwe (Rurinda et al., 2015). The northern part of the country has been experiencing a late start to the rainy season by as much as eighteen days (Government of Zimbabwe, 2020). In contrast, the southern part of has shifted towards an early start to the rainfall season. While the rainfall has been observed to be starting late in the northern part and early in the southern part, the rainy season is ending early across the country (Spear et al., 2018). This has resulted in a decrease of rainy days and consequently, the contraction of the rainy season, a situation that is affecting water availability for crop and livestock production.

About sixty per cent of Zimbabwean population is concentrated in rural areas, while about seventy per cent of its employment is directly or indirectly accounted for by agriculture, which is largely rainfed (UNICEF, 2015). As such, greater part of the population survive on rainfed farming system (Fachrista et al., 2019). The negative impacts of CVC call for transformational changes in farming systems that will contribute to sustainable development in Zimbabwe. In addition, a robust agricultural sector will enhance national food security while providing inputs for the industrial sector. Unfortunately, Zimbabwe has not sufficiently harnessed available scientific knowledge to increase productivity, stimulate industrial growth, and penetrate regional 
and global markets to diversify its rural livelihood (Masunungure \& Shackleton, 2018; Mlambo, 2017). The impacts of CVC continue to present challenges to many farmers who lack appropriate response measures. Designing policies that improve agricultural productivity calls for an understanding of farmers' perception of climate change. This study therefore, examined farmers' perceptions on CVC in Zimbabwe's intensive farming region; and compared the perceptions to observed historical climate data in order to establish an appropriate basis for adaptation strategies. It provides answers to three questions: (1) what are the perceptions of local farmers to CVC and how do these perceptions reflect the observed historical climate data? (2) What are the perceived impacts of CVC on rural livelihoods; and (3) what adaptation practices (if any), are the farmers taking to enhance their food security? By answering these questions, this study contributes to existing literature that measures the strength of local famers' perceptions on CVC in order to minimise its hostile impacts. Unlike other studies that have focused on smallholder farmers in arid and semi-arid areas in Zimbabwe, this research is focused on commercial farmers in the most cropproductive agro-ecological region of the country.

After this introduction, section two reviews the literature on CVC adaptation. This is followed by a description of the study area, methods used in gathering data and its analysis. Sections four and five will present and discuss the results respectively. Lastly, the paper will provide a conclusion and some policy implications.

\section{Climate variability and change and famers' adaptation behaviour}

Predictions point to an increase in CVC that are characterised by extreme weather conditions in Southern Africa (Mubaya et al., 2012). At the same time, research has shown that agriculture is very sensitive to a changing climate (Masud et al., 2017). The most impacts of CVC on agriculture include increased food insecurity and reduced productivity. In order to minimise these effects and others, famers have to adapt their faming systems to the changing climate. CVC adaptation involves making long-term adjustments in the socio-ecological systems in response to actual or perceived climatic conditions in order to prevent or to mitigate the associated risks (Alam et al., 2017). Since CVC impacts differ from one place or community to another, the adaptation strategies also vary depending on the agro-ecological system under attack, socio-economics of the farmers, existing capacities of the farmers at risk, and their own perceptions of climate change (Elum et al., 2017).

The link between farmers' perceptions and CVC adaptations is not straightforward. Some studies report that farmers' perceptions positively influence adaptation strategies. For example, the majority of crop farmers who perceived CVC risk in the US Midwestern region were more willing to implement in-field and edge-of-field conservation practices, and diversify into other forms of production than other farmers (Mase et al., 2017). In a similar way, smallholder farmers in the Limpopo Province of South Africa who perceived remarkable changes in rainfall timing and amount were quick to diversify their crops and apply mulching (Rankoana, 2016). In Ghana, the farmers' perceptions of CVC at local levels were used to identify specific requirements for strengthening local adaptation strategies (Kusakari et al., 2014). However, other studies show many farmers who failed to adapt despite perceiving CVC as a real threat. For example, not all Bangladeshi households who perceived extreme climatic events on their livelihoods undertook adaptation strategies including the adoption of new crop varieties and changing planting time (Alam et al., 2017). Likewise, Zamasiya et al. (2017) observed that the majority of Zimbabwean smallholder farmers with high perception of CVC failed to implement recommended adaptation strategies due to lack of resources. These cases show that CVC adaptation is determined by many factors other than perceptions alone. Notwithstanding that, Masud et al. (2017) posit that farmers need to be convinced that climate is changing in order to take appropriate adaptation strategies. Adapting to CVC may reduce farmers' vulnerability and enhance their resilience to climate stressors and shocks. This is supported by research from Bangladesh which reported that a significant number of farmers with informed CVC knowledge had high potential to support policies and programmes aimed at addressing CVC (Alam et al., 2017). Misconceptions about CVC can lead to complacency and or, inappropriate changes in farming systems. Therefore, a proper understanding of farmers perceptions of $\mathrm{CVC}$ will lead 
to a better understanding of the strategies they adopt in order to improve food security.

The adverse impact of CVC in the Global South is high in the agricultural sector, the key livelihood for many (Fachrista et al., 2019). Apart from reducing agricultural outputs, CVC increases the outbreaks of pests and diseases and reduces the availability of both ground and surface water. The famers' capacity to adapt to CVC depends on their access to information, technology, institutions and policies among others (Bahinipati, 2014; Wood et al., 2014). For example, vegetable farmers in Central Java, Indonesia who had acquired climate change information collaborated with local research institutions in implementing a range of adaptation strategies (Fachrista et al., 2019). Planned adaptation ensures that actions taken on local or wide scale reduce climate risk. An examination of famers' perceptions on CVC may lead to an understanding of the adaptation strategies. Some of the adaptation strategies that have been implemented at local levels in Ghana and India include planting different crops, water conservation, changing planting dates, soil conservation, tree planting, and irrigation (Ndamani \& Watanabe, 2015; Tripathi \& Mishra, 2017). Although many studies on CVC adaptation exist in Zimbabwe and other countries of the Global South, the majority of them have focused on arid and semi-arid environments (Yadav \& Lal, 2018). Very few studies have focused on agro-ecological regions that are conducive for intensive farming.

Although proper information can change famers' practices and attitudes, the decision to embrace new farming strategies is also influenced by other factors. One of the factors is the capacity of individual farmers, which usually vary from one farm to another. In farming systems, the term capacity is very broad. It includes economic resources, social capital, awareness and training, technology, infrastructure and institutions (Abdul-razak \& Kruse, 2017). These factors are neither independent nor mutually exclusive. Instead, they operate as a system, influencing each other and being influenced by others. Any new farming strategy usually comes with costs, which is another factor that influence the decision to adapt to CVC. Usually famers conduct a cost-benefit analysis prior to deciding on the new strategy. If the benefits outweigh the costs, most famers are likely to embrace the strategy. Determining if the benefits are going to exceed the costs is one of the most difficult decision for most farmers in
California, US due to uncertainties in climate events (Tortajada et al., 2017). Yet failure to adapt to CVC is again associated with uncertainties, including getting out of the farming business. As found in Malaysia, other barriers that constrain famers' decision to adapt to CVC include limited expertise, technology, and lack of institutional support (Masud et al., 2017). The adaptive capacity of farmers is determined by a range of factors, which result from a combination of socioeconomic, environmental and institutional factors.

Empirical data from farmers experiencing extreme weather events should inform adaptation policies and practices because the practices are location-specific. For example, in response to rainfall variability during the wet season, farmers in India adopted the use of PVC pipes to carry underground water for irrigation in farms (Tripathi \& Mishra, 2017), whilst those in Ethiopia resorted to destocking and moving with animals in search of pastures and water (Tessema \& Simane, 2020). Agricultural policies should consider views of the farmers on adaptation strategies for the policies to be accepted and operationalised. For example, limited knowledge about agricultural subsidies in Malaysia was one of the challenges faced by farmers in their adaptation to CVC (Masud et al., 2017). Therefore, an understanding of farmers' perceptions on local changing climate can enhance policy formulation which are specific to identified areas.

\section{Materials and methods}

\section{Study area}

This study area is the agro-ecological region two (AE2) of Zimbabwe (Fig. 1). This region covers about fifteen per cent of Zimbabwe, spanning across Marondera, Goromonzi, Mazowe, Bindura, Makonde and some part of Zvimba districts (Government of Zimbabwe, 2020). Because the region is very wide, only two districts of Mazowe and Bindura were chosen based on their ease of access during the distribution of questionnaires. Rainfall in this region is confined to summer (November-March) and is moderately high (750-1000 mm) (World Bank, 2019). The region is suitable for all farming systems including dairying, horticulture, poultry, piggery, beef, fruit and crop production. Livestock production is generally intensive and based on pastures and pen fattening. Major 


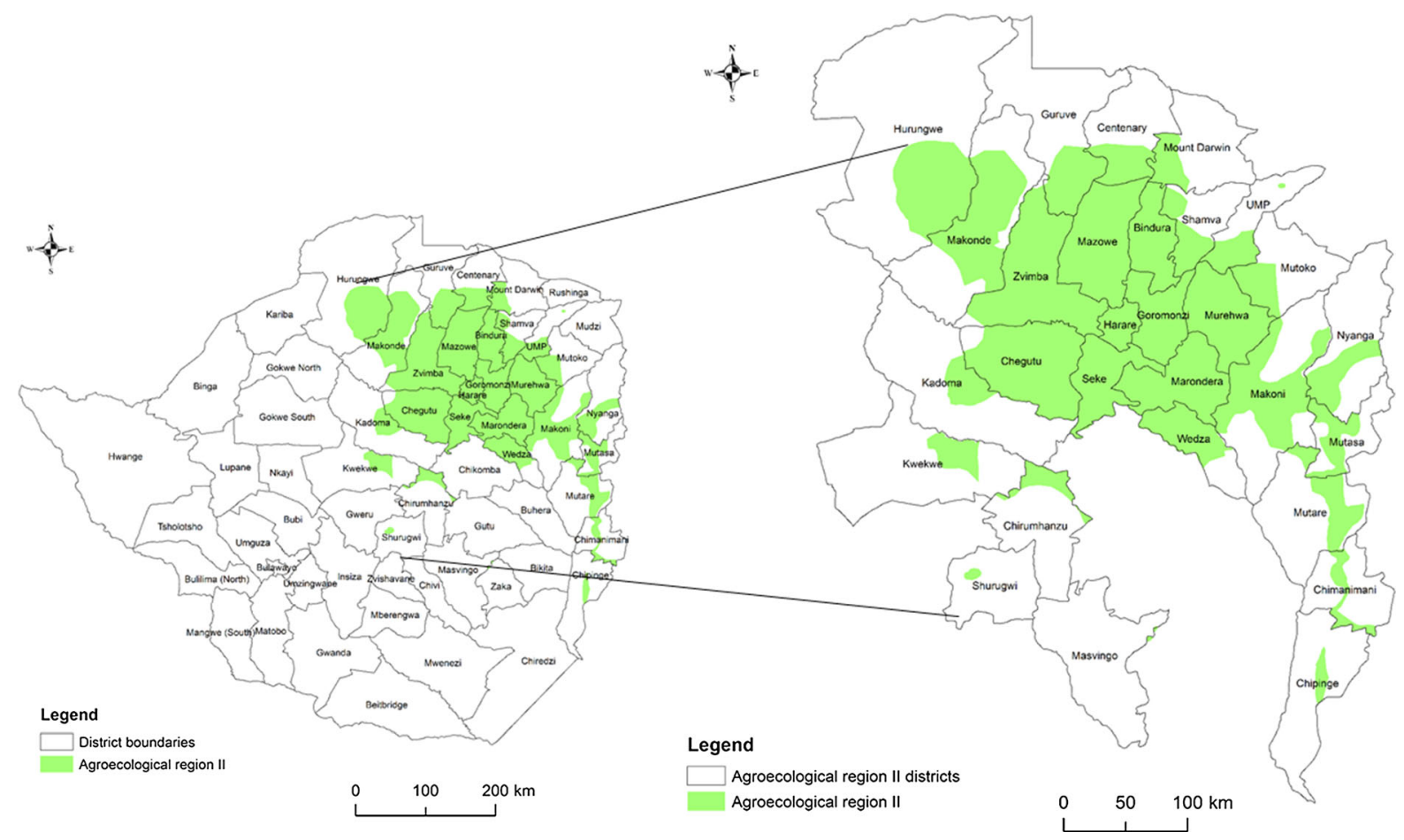

Fig. 1 Study area

crops grown include maize, seed maize, tobacco, wheat, soya beans and cotton. Wheat and barley production is practiced under irrigation during the dry period of May to September (Jiri \& Mafongoya, 2018). As a result, the region is the main granary area of Zimbabwe. Large-scale white commercial farmers and estates dominated AE- 2 before the fast-track land reform programme of 2000. Today, black farmers have been resettled in the region under the categories of AI (large-scale famers) and A2 (smallholder farmers).

The two districts have an estimated population of 410000 of which about 11 per cent is urban (ZIMSTAT, 2017). As such, greater part of the population survives on farming. The average life expectancy of the population is estimated at 59 years while the crude death rate is about 12.2 per 1000 , and the infant mortality rate was estimated at 77 deaths per 1000 births (ZIMSTAT, 2017). The rates are higher in rural than in urban areas due to poor living conditions. The poverty prevalence in the two districts is $65 \%$ (ZIMSTAT, 2015). The rural areas are also characterised by insufficient public utility infrastructure, poor transport, education and health services
(Muchabaiwa et al., 2017). In addition to agriculture, mining forms an economic pillar of the study area with large-scale mining of gold and nickel at Fredda Rebecca and Trojan Mine respectively. There are also illegal artisanal gold panners throughout the two districts. Most of the illegal gold panners often work in a nomadic manner targeting auriferous reefs, abandoned mines, river sides, old workings and dumps (Mavhura, 2019). Since artisanal mining is not regulated, poor working conditions prevail and illegal structures and settlements have emerged around the mining claims.

Despite being in an intensive farming region, the two districts are also prone to climate change. Drought, long dry-spells, localised intense precipitation and storms affect the districts (Frischen et al., 2020). The changes in climate are likely to affect the national food security if the current cohort of farmers fail to adapt accordingly. Currently, irrigation is limited in the region, although water infrastructure developed by the former white commercial farmers still exist. Consequently, the new farmers entirely rely on rainfed farming, which is very sensitive to CVC and variability. In view of this, it is important to 
understand farmers' perceptions and adaptation measures to climate change.

\section{Research approach and design}

This study used a quantitative approach to collect data (Almalki, 2016). The approach involved a crosssectional survey using structured questionnaires (Yin, 2009), which enabled obtaining detailed answers to the perceived impacts of CVC and the related adaptation strategies.

\section{Population and sample}

The total population of commercial farmers in the study area was 1650 . The list of the farmers was availed by the Department of Agricultural Extension in the province. About $54 \%$ of the farmers came from Mazowe district while the remainder (46\%) were from Bindura district. In an effort to reach as many farmers as possible during the survey, the study targeted a quarter of the commercial farmers in the area. It first applied cluster sampling by dividing the farmers into their respective districts. Then, a simple random sample of $25 \%$ was drawn from each district. However, only a sample of 365 farmers, which constituted about $22 \%$ of the farmer population, finally participated in the survey.

Data sources

Primary data came from a cross-sectional survey targeting farm owners or managers in Mazowe and Bindura districts. Three hundred and sixty-five respondents participated in the survey during the harvesting period of May to August 2019. Where the farm owner or manager was absent, arrangements were made for later return calls in person. The survey employed a structured questionnaire that mainly sought three categories of data, namely (a) farmer perceptions using ten CVC parameters, (b) perceived CVC impacts on livelihood capitals, and (c) adaptive strategies that the farmers were taking. The ten CVC parameters included drought frequency and severity, mean annual rainfall and temperature, length of dry and rainy seasons, frequency of natural veldt fires and cyclonic events, and availability of ground and surface waters. These parameters and the perceived impacts on livelihoods were gathered using a 4-point Likert Scale: increase, decrease, no change and do not know. The 'no change' and 'do not know' options reduced the bias of acquiescence (Valencia, 2020) that was likely to emerge among the survey respondents. The two also minimised the attrition and other problems of misreporting or under-reporting based on social desirability. In the case of adaptation strategies, the respondents ticked the strategies they were practicing from a given list. In this way, the study was able to identify common strategies employed by farmers to cope with CVC.

Secondary data on precipitation and temperature came from the meteorological office of Zimbabwe. The data belonging to two weather stations (Henderson, Mazowe and Bindura Railway, Bindura) in the study area covered the period 1950 to 2018 . The data was used to compare the farmers' perceptions with the observed climatic trends. However, the Bindura station did not have temperature data backdating to 1950. As a result, temperature data for one district was used for the comparative analysis.

\section{Data analysis}

The data was first analysed using descriptive statistics and a weighted four-point Likert Scale. We used descriptive statistics to determine the level of farmers' perceptions on each CVC indicator and the perceived impacts. Then a Likert Scale with weights ranging from 4 to 1 were assigned to each response category (Increased, No Change, Don't Know and Decreased respectively). The weighted mean for each variable was calculated using the equation:

Weighted Indicator Mean $=\frac{\sum n_{r c i} w_{r c i}}{N}$

where, $n_{r c i}$ is the number of respondents in each category; $W_{r c i}$ is the weight value of each category; and $\mathrm{N}$ is the total number of respondents.

After having determined the weighted indicator mean, we calculated the weighted mean of farmers' perceptions on CVC indicators (WFPM) using the equation:

$W F P M=\frac{\sum w v m}{n}$ 
where $w v m$ is the sum of the weighted indicator mean; and $n$ is the number of indicators measuring farmers' perceptions.

The weighted mean for each perceived impact of CVC on rural livelihoods (WPIM) was calculated using the equation:

$W P I M=\frac{\sum n_{r c i} w_{r c i}}{N}$

where, $n_{r c i}$ is the number of respondents in each category; $W_{r c i}$ is the weight value of each category; and $N$ is the total number of respondents.

Likewise, after having determined the weighted mean of each perceived impact, we calculated the weighted mean each livelihood capital (WMLC) using the equation:

$W M L C=\frac{\sum w p i m}{n}$

where wpim is the sum of the weighted mean livelihood impact; and $n$ is the number of indicators measuring each livelihood asset.

In this way, the study quantified precisely the level of farmers' perception of CVC and its impact on their livelihood assets. The final scores ranged from 1 (poor) to 4 (excellent). The scores were classified as: 1 = poor; 2 = fair; $3=$ good and $4=$ excellent.

The secondary rainfall and temperature data was subjected to trend analysis to establish the changing patterns. The study also used Vensim PLE 7.2 software to draw a stock-flow diagram, which showed the percevied cascading impact of CVC on farmers' livelihoods. This software was suitable for this anlaysis due to the nonlinear and complex interactions of CVC with rural livelihoods (Lane et al., 2016). However, to simplify the diagram, only the top ten perceived impacts were coonsidered in the analysis.

\section{Ethical considerations}

The ethical committee of the institution of the principal author approved the survey questionnaire. Prior to its use, the questionnaire was subjected to content validity and pre-test (Male, 2016) with the help of research assistants. This improved the adequacy of the data obtained and reduced number of items with ambiguity. The research assistants were all MSc students who were able to interpret the questionnaire items correctly. However, none of them came from the study area. This minimised social bias during the data gathering process. The research assistants went through a rigorous training on conducting the survey. This included establishing rapport, maintaining neutrality and handling unanticipated emotions (Arsel, 2017). Informed consent was verbally sought on individual respondent (Mcgrath et al., 2018). Each survey lasted for about one and half hours on average.

\section{Findings}

The findings are presented in three sections: farmers' perceptions of climate change, perceived impact on rural livelihoods, and the related adaptive strategies.

\section{Famers' perceptions of local climate change versus observed historical climate data}

Most famers were aware of the changing climate (Table 1). From the frequency and severity of drought through to availability of surface and ground water, the majority of the surveyed farmers reported that they had perceived significant changes in the past years. As shown in Table 1, nine of the 10 CVC indicators' weighted mean scores ranged from 3.05 to 3.98 out of a maximum score of 4 . This shows that the farmers' perceptions on CVC were very high. Only one parameter was rated fair. Table 1 also shows that none of the respondents perceived an increase in precipitation or a reduction in temperature. The lengths of the rainy and dry seasons were perceived to have shortened and increased respectively by about $93 \%$ of the respondents. The overall weighted mean of the farmers' perceptions on CVC also showed that the famers were conscious of the changing climate.

These perceptions were consistent with the observed rainfall and temperature trends of the study area. Figures 2 and 3 show decreasing rainfall amounts from 1950 to 1918 in Mazowe and Bindura districts respectively. In addition, Fig. 4 shows the trends in maximum, minimum and mean temperatures for the Mazowe district. The three have been slightly increasing over the decades, which is consistent with farmers' perceptions. 
Table 1 Farmer perceptions on climate variability and change indicators $[\mathrm{n}=365 ;(\%)]$

\begin{tabular}{|c|c|c|c|c|c|}
\hline Indicator & Increased & No change & Don't know & Decreased & Weighted mean \\
\hline Frequency of drought & $358(98.1)$ & $5(1.4)$ & $2(0.5)$ & $0(0.0)$ & 3.98 \\
\hline Severity of drought & $358(98.1)$ & $5(1.4)$ & $2(0.5)$ & $0(0.0)$ & 3.98 \\
\hline Reduced annual rainfall & $316(86.6)$ & $33(9.0)$ & $16(4.4)$ & $0(0.0)$ & 3.82 \\
\hline Mean annual temperature & $274(75.1)$ & $80(21.9)$ & $11(3.0)$ & $0(0.0)$ & 3.72 \\
\hline Short rainy seasons & 339 (92.9) & $23(6.3)$ & $3(0.8)$ & $0(0.0)$ & 3.92 \\
\hline Length of dry seasons & 339 (92.9) & $21(5.8)$ & $5(1.4)$ & $0(0.0)$ & 3.92 \\
\hline Frequency of natural veldt fires & $143(39.2)$ & $137(37.5)$ & $45(12.3)$ & $40(11.0)$ & 3.05 \\
\hline Frequency of cyclonic events & $156(42.7)$ & $95(26.0)$ & $12(3.3)$ & $102(27.9)$ & 2.84 \\
\hline Reduction in groundwater supply & $177(48.5)$ & 145 (39.7) & $43(11.8)$ & $0(0.0)$ & 3.37 \\
\hline Reduction in surface water supply & $214(58.6)$ & $123(33.7)$ & $28(7.7)$ & $28(7.7)$ & 3.51 \\
\hline \multicolumn{5}{|c|}{ Overall weighted mean of farmers' perceptions on climate change } & 3.61 \\
\hline
\end{tabular}

Fig. 2 Annual rainfall trends for Mazowe district, Zimbabwe ( Source: Meteorological Office, Zimbabwe)

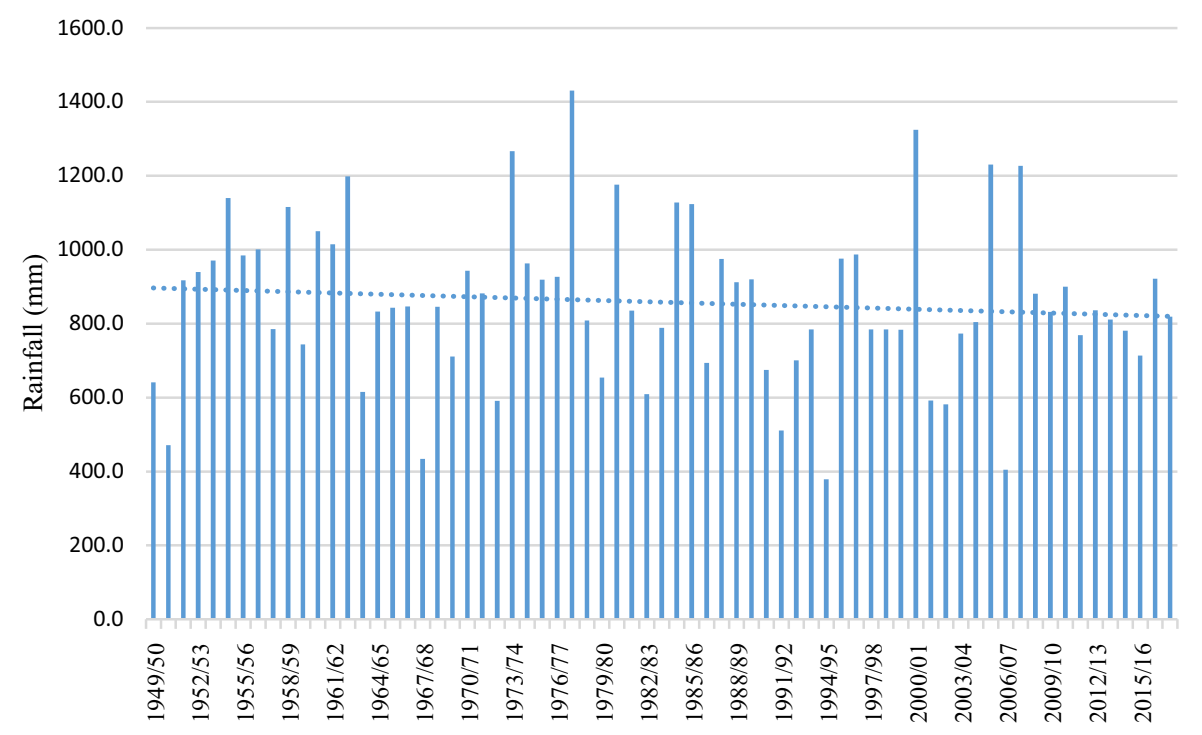

Perceived impacts of climate variability and change on rural livelihoods

The farmers perceived that CVC was affecting their livelihood capitals (Table 2). The most significant changes were observed among the natural and economic capitals. Soil salinization and reduction in grazing pastures and fodder were the major perceived impacts of the natural capital. Under the economic capital, reduction in crop yields and increases in food prices were the key impacts perceived by about $86 \%$ and $85 \%$ of the respondents. Climate changes and variability also affected other variables of the physical, social and human assets. For example, food insecurity/malnutrition and unemployment have been perceived to be on the rise while cooperation among the farmers was perceived to be falling. The use of weights on each response category enabled quantifying each perception and the perceived impacts as well as the overall perception and livelihood capital.

The use of the descriptive statistics in conjunction with the Likert Scale also enabled the subjective ranking of the perceived impacts of CVC. The study used the descriptive statistics of the 'increase' scale to rank the 18 perceived impacts. The top ten impacts emerged as (1) Reduction in crop yields (86.3\%), (2) Increase in food prices $(85.2 \%)$, (3) Food insecurity/malnutrition (85.2\%), (4) Reduced incomes 
Fig. 3 Annual rainfall trends for Bindura district, Zimbabwe ( Source: Meteorological Office, Zimbabwe)

Fig. 4 Temperature trends for Mazowe district, Zimbabwe ( Source Meteorological Office, Zimbabwe)
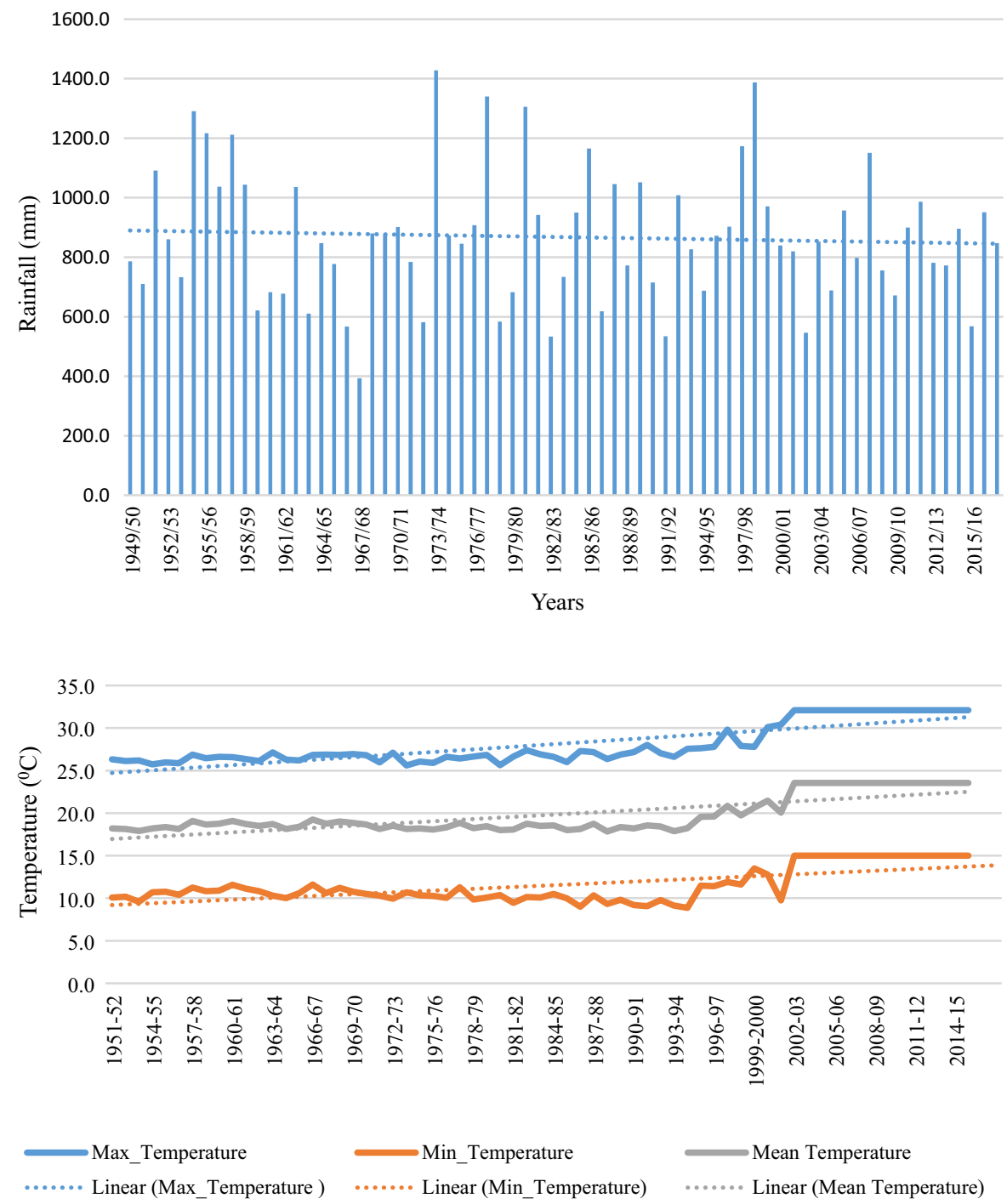

(82.2\%), (5) Increased crop insurance (63.8\%), (6) Soil salinization $(57.5 \%)$, (7) Loss of grazing pastures and fodder $(55.1 \%),(8)$ Loss of forestry $(54.5 \%)$, (9) Unemployment (54.5\%) and (10) Reduced ability to save $(53.4 \%)$. The farmers explained that CVC affected their livelihoods in complex, direct and indirect ways. As shown in Fig. 5, CVC reduce crop yields, grazing pastures and fodder while increasing soil salinization. This creates cascading effects on the rest of the livelihood capitals. For example, food insecurity, unemployment and crop insurance increase. Figure 5 also shows four positive reinforcing loops- $\mathrm{R}_{1}, \mathrm{R}_{2}, \mathrm{R}_{3}$ and $\mathrm{R}_{4}$ that farmers identified during the interviews. The loops emerged when an increase in one variable increased the other variable.
For example, in $\mathrm{R}_{1}$, a reduction in crop yields resulted in reduced income, which further caused a reduction in crop yields when farmers fail to invest in irrigation infrastructure that has the potential to offset the impact of dry spells. Other positive reinforcing loops identified by farmers include those between loss of overgrazing pastures/fodder and reduced ability to save $\left(\mathrm{R}_{2}\right)$; unemployment and reduced ability to save $\left(\mathrm{R}_{3}\right)$; and reduction in crop yields and unemployment $\left(\mathrm{R}_{4}\right)$.

Farmers' adaptation practices

Despite facing increased impacts of CVC, the farmers who observed climate change were responding to the 
Table 2 Perceived impacts of climate variability and change on rural livelihoods $[\mathrm{n}=365 ;(\%)]$

\begin{tabular}{|c|c|c|c|c|c|c|}
\hline \multirow[t]{2}{*}{ Livelihood asset } & \multirow[t]{2}{*}{ Impact } & \multicolumn{4}{|c|}{ Respondents' responses } & \multirow[b]{2}{*}{$\begin{array}{l}\text { Weighted } \\
\text { Mean }\end{array}$} \\
\hline & & Increase & No change & Don't know & Decreased & \\
\hline \multirow[t]{6}{*}{ Natural } & Loss of arable land & $185(50.7)$ & $100(27.4)$ & $65(17.8)$ & $15(4.1)$ & 3.25 \\
\hline & Reduction in ground and surface waters & $165(45.2)$ & $145(39.7)$ & $43(11.8)$ & $12(3.3)$ & 3.37 \\
\hline & Loss of forestry & $199(54.5)$ & $123(33.7)$ & $28(7.7)$ & $15(4.1)$ & 3.39 \\
\hline & Loss of grazing pastures and fodder & $201(55.1)$ & $120(32.9)$ & $30(8.2)$ & $14(3.8)$ & 3.39 \\
\hline & Soil salinization & $210(57.5)$ & $100(27.4)$ & $36(9.9)$ & $19(5.2)$ & 3.37 \\
\hline & Weighted Mean - Natural Capital & & & & & 3.35 \\
\hline \multirow[t]{4}{*}{ Physical } & Poor animal health & $113(31.0)$ & $130(35.6)$ & $24(6.6)$ & $98(26.8)$ & 2.71 \\
\hline & Farm infrastructure damage from hailstorms & $55(15.1)$ & $211(57.8)$ & $38(10.4)$ & $61(16.7)$ & 2.71 \\
\hline & Road infrastructure damage from severe storms & $165(45.2)$ & $150(41.1)$ & $8(2.2)$ & $42(11.5)$ & 3.20 \\
\hline & Weighted Mean - Physical Capital & & & & & 2.87 \\
\hline \multirow[t]{5}{*}{ Human } & Poor health leading to limited productivity & $45(12.3)$ & $166(45.5)$ & $136(37.3)$ & $18(4.9)$ & 2.65 \\
\hline & Food insecurity/malnutrition & $311(85.2)$ & $20(5.5)$ & $7(1.9)$ & $28(7.7)$ & 3.69 \\
\hline & Unemployment & $199(54.5)$ & $116(31.8)$ & $44(12.1)$ & $6(1.6)$ & 3.39 \\
\hline & Seasonal migration of labour force & $185(50.7)$ & $33(9.0)$ & $26(7.1)$ & $121(33.2)$ & 2.277 \\
\hline & Weighted Mean - Human Capital & & & & & 3.13 \\
\hline \multirow[t]{2}{*}{ Social } & Limited co-operation among farmers' groups & $166(45.5)$ & $135(37.0)$ & $55(15.1)$ & $9(2.5)$ & 3.25 \\
\hline & Weighted mean - Social Capital & & & & & 3.25 \\
\hline \multirow[t]{6}{*}{ Economic } & Reduction in crop yields & $315(86.3)$ & $25(6.8)$ & $18(4.9)$ & $7(1.9)$ & 3.78 \\
\hline & Reduced incomes & $300(82.2)$ & $5(1.4)$ & $5(1.4)$ & $55(15.1)$ & 3.51 \\
\hline & Reduced ability to save & $195(53.4)$ & $99(27.1)$ & $51(14.0)$ & $20(5.5)$ & 3.28 \\
\hline & Increased crop insurance & $233(63.8)$ & $25(6.8)$ & $4(1.1)$ & $3(0.8)$ & 2.79 \\
\hline & Increase in food prices & $311(85.2)$ & $25(6.8)$ & $28(7.7)$ & $1(0.3)$ & 3.77 \\
\hline & Weighted Mean - Economic capital & & & & & 3.43 \\
\hline
\end{tabular}

threats by adopting one or more strategies. The study revealed nine adaptation strategies adopted by the farmers based on their local knowledge of the changing climate (Fig. 6). As shown in Fig. 6, the most common strategies include farm diversification, cultivation of short-seasoned varieties, irrigation and changing planting time. However, the majority of the farmers have adopted multiple strategies in order to remain in business. All these strategies are in response to drought, dry spells and increasing temperatures. None of the adaptation strategies was in response to cyclonic activities.

\section{Discussion}

This study's findings clearly revealed that farmers' perceptions of CVC were cognate with data from the meteorological office. This is a significant new finding as meteorological observations by farmer's and their perceptions of CVC intersect to the point where they fully understand the challenges and risks associated with CVC so that they can respond in a more efficient manner. In short, their perception of CVC is supported by scientific climate data. The comparison was necessary because perception studies face the challenge of memory decay of past climatic conditions (Makuvaro et al., 2018). From the current study, it is possible to conclude that farmers were well aware of the changing climate conditions in their locality. Similar findings were reported in Western Tanzania (Kangalawe et al., 2017). Major CVC impacts perceived by the farmers in the current study include food insecurity, unemployment and increasing prices of food. In response to the perceived changes, farmers adopted a range of crop and land use management 


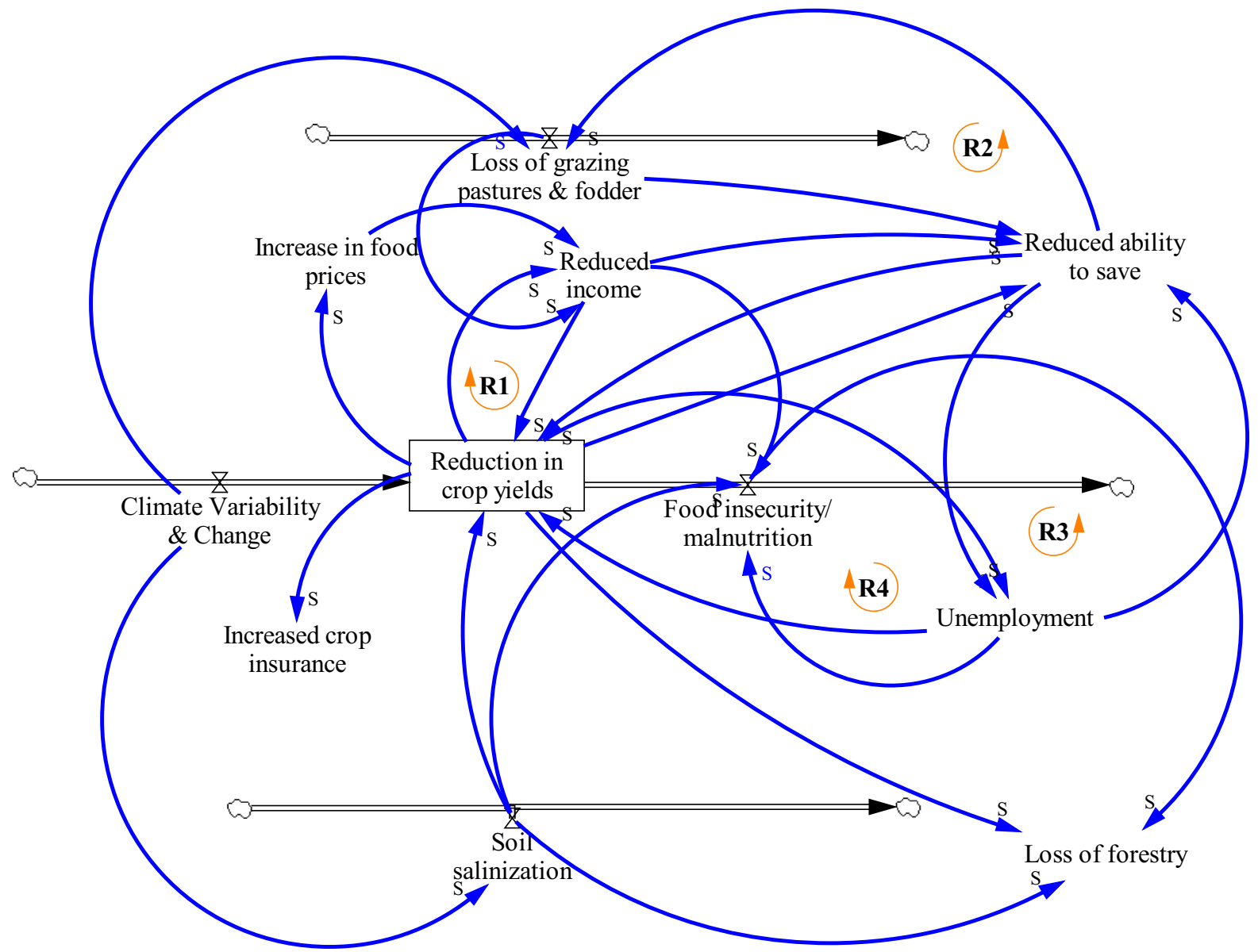

Fig. 5 Cascading impacts of climate variability and change on farmers' livelihoods. NB: The letter "S" at the arrowheads mean "support" and "R," means reinforcing

strategies. Crop management strategies included planting rotation, cultivation of short-season varieties and drought tolerant crops in addition to crop diversification. Land use strategies included intensified irrigation, farm diversification, agroforestry, soil moisture conservation and mixed farming. These findings confirm the observations made by Moyo et al. (2012) that farmers' perceptions regarding CVC in semi-arid Zimbabwe influence decisions in farm management. However, none of the adaptation strategies observed in the current study was in response to cyclonic activities. Rather, they were all in response to deficits in rainfall and extremes in temperatures. The strategies utilised by farmers in AE-2 were likewise observed to be common among peasant farmers in arid areas of Zimbabwe (Mavhura et al., 2017; Mutandwa et al., 2019).
Reduction in crop yields was perceived as the biggest impact of CVC. The reduction was also observed by the Zimbabwe National Statistical Agency (ZIMSTAT, 2019). This is the most popular impact perceived by farmers in Southern Africa. For example, farmers in the provinces of Gauteng, Limpopo and Mpumalanga of South Africa reported significant losses in crop yields induced by CVC (Elum et al., 2017). Similarly, smallholder farmers in Chirumanzu district, Zimbabwe indicated that reduced crop yields were the major impact of CVC (Manyani et al., 2017). The same perceptions were also observed in Tanzania and Uganda (Kangalawe et al., 2017; Okonya et al., 2013). Related to crop yields reduction is the loss of grazing pastures and fodder affecting livestock production including dairying and beef. CVC reduces rainfall and consequently vegetative growth in the grazing lands (Muzari et al., 2014). The 


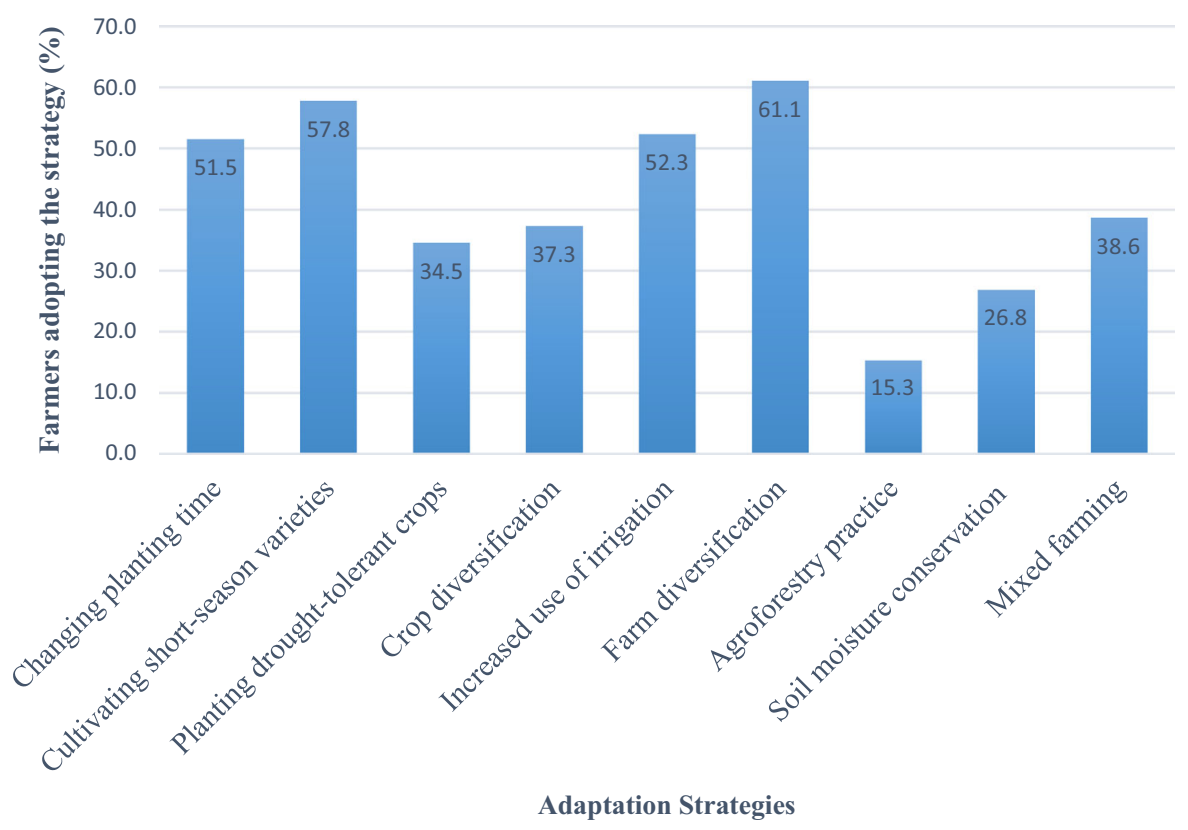

Fig. 6 Farmers' adaptation practices

variability of rainfall timing, amount and duration were also found with negative effects on livestock production in the Ethiopian highlands (Yayeh \& Leal, 2017). Due to its impact among African pastoralists, loss of grazing pastures and fodder is considered as part of the indigenous knowledge system of CVC (Mafongoya \& Ajayi, 2017).

Our results are also consistent with other researches on CVC perceptions and adaptation strategies (Mase et al., 2017; Muzari et al., 2016). In Indonesia, Fachrista et al. (2019) observed a positive correlation between the perceptions of organic vegetable farmers regarding CVC with the amount of adaptation strategies applied by the farmers to reduce the impact of climate change. The studies indicate that people who perceive CVC are likely to adopt adaptative strategies to minimise its negative impact. Hence, promoting farmers' awareness of CVC enhances the adoption of appropriate adaptation strategies. Adaptation seems to be a better option for developing countries because of the relatively low costs involved. However, its main challenge is the limited capacity among the at risk farmers and their respective governments (Tripathi \& Mishra, 2017). For adaptation to be effective, two factors need consideration. First, farmers must first be convinced that CVC exists, (i.e., they should perceive the risk associated with $\mathrm{CVC}$ ). Second, the farmers must be willing and have the capacity to respond to the perceived impacts. Such measures can include crop, land use and livestock management strategies in addition to engaging in non-climate dependent livelihoods (Mavhura et al., 2017). However, all non-farm activities need to be balanced with climate-smart forms of agriculture so as to improve food security (Dumenu \& Obeng, 2016). Farmers who adopt climate-smart agriculture including investments in irrigation and water conservation technologies have been observed to improve food production in places prone to changing climate (Khoza et al., 2019).

This study has also measured farmers' perceived impact of CVC on their livelihoods. The use of Vensim PLE 7.2 analysis technique revealed some casscading effects of CVC on farmers livelihoods. This is due to the fact that the livelihoods operate as a system where an effect on one component affects the other (Coulibaly et al., 2015). Similarly, Moyo et al. (2012) reported that famers' perceptions are determined by the impact of CVC on their livelihoods. The quantification of perceived impacts has revealed many variables that need capacity building for the farmers to enhance their production. This supports Mavhura (2017)'s argument that the resilience of rural communities depends mostly on their access to and wise use of livelihood capitals. The variables that need to be 
addressed include loss of surface and ground water, food insecurity and increasing food prices. Therefore, this assessment can pave the way for policy makers to intervene with appropriate measures that improve farmers' resilience to climate change. However, since the capitals are inter-linked, the intervention measures should address the livelihood assets as a system. This means addressing more than one component or livelihood of the farming systems at the same time. Doing so is important because livelihood capitals operate as an integrated system, where a negative or positive impact on one asset would affect other capitals (Mavhura, 2017). For example, creating irrigation infrastructure can contribute to food security, improve incomes and create employment (Antwi et al., 2015). Thus, a systems approach is useful in improving farmers' resilience because many of the factors are covariant. Another advantage of a systems approach is its focus on nonlinear interactions among capitals building resilience (Mock et al., 2015). This is crucial as farmers are not passive victims of climate change. However, the current study lacks qualitative data to consider how livelihood capitals influence the adaptation strategies adopted by farmers.

The consideration of farmers' perceptions of CVC in the current study provides very useful insights to stakeholders in the agriculture sector. First, the perceived impacts pose a serious threat to food security, particularly maize, the staple food in Zimbabwe. Therefore, the shift to short-seasoned and or, drought-tolerant cultivars of maize and other food crops should be considered as an adaptation priority by farmers across various agroecological zones of the country. In fact, famers need to adapt their operations to the changing climate in order to minimise CVC impacts, reduce farmers' vulnerability and enhance their resilience to climate stressors and shocks. The adaptations may involve a range of crop and land use management strategies. In order to ensure a full implementation of the adaptation strategies, government support is required. In addition to adapting a variety of crop and land use management practices, farmers need training in using weather forecasts to enable them to adjust their operations based on seasonal rainfall forecasts. Those farmers who solely rely on rain-fed farming to produce food, require additional support to enable them to intensify irrigation. This should not be a big challenge because white commercial farmers developed a lot of irrigation infrastructure prior to the land reform programme in Zimbabwe. Such infrastructure is currently underutilised. Furthermore, the farmers' perceptions in the current study capture context-specific concerns regarding food production. They provide answers to queries regarding $\mathrm{CVC}$ risks or livelihood impacts, and the effective adaptation strategies at the agroecological level. Such specific information may need to be up-scalable to the national context in order to avert famine and hunger. Hence, the farmers' perceptions of the current study provide supportive evidence to informed policy on farming options.

\section{Conclusion}

Although this research is largely confirmatory of perceptions of CVC in other areas in Africa, it reenforces the fact that in the context of Zimbabwe, specifically in regard to farmers adopting a variety of crop and land use management strategies, it is imperative for policy makers to support farmers in their efforts. Zimbabwe's farmers have, whether they realize it or not, been responding to the risks from $\mathrm{CVC}$ and thus can be used as an example to farmers in other regions to emulate. Farmers should be confident that their perceptions of CVC mirror the scientific data obtained through official government entities. Therefore, they can go forward and modify their agricultural calendar and diversify their farming systems so as to better meet current and future risks from CVC. This includes changing planting times, selecting crops and livestock varieties which are ideal for each farming season, and using supplementary sources of moisture to offset the negative effects of erratic precipitation. Doing so will enhance the resilience of farming.

\section{Declarations}

Conflict of interest We hereby declare that there is no conflict of interest whatsoever related to this manuscript.

Involvement of human participants and animals There has been no involvement of animals in this research. The human participants' consent was requested prior to undertaking this research.

Informed consent The human participation in this research was in form of responding to questionnaires and interviews. The participants were aged eighteen years and above and consent was requested before the research. 
Open Access This article is licensed under a Creative Commons Attribution 4.0 International License, which permits use, sharing, adaptation, distribution and reproduction in any medium or format, as long as you give appropriate credit to the original author(s) and the source, provide a link to the Creative Commons licence, and indicate if changes were made. The images or other third party material in this article are included in the article's Creative Commons licence, unless indicated otherwise in a credit line to the material. If material is not included in the article's Creative Commons licence and your intended use is not permitted by statutory regulation or exceeds the permitted use, you will need to obtain permission directly from the copyright holder. To view a copy of this licence, visit http://creativecommons.org/licenses/by/4.0/.

\section{References}

Abdul-razak, M., \& Kruse, S. (2017). The adaptive capacity of smallholder farmers to climate change in the Northern Region of Ghana. Climate Risk Management, 17, 104-122. https://doi.org/10.1016/j.crm.2017.06.001

Alam, G. M. M., Alam, K., \& Mushtaq, S. (2017). Climate change perceptions and local adaptation strategies of hazard-prone rural households in Bangladesh. Climate Risk Management, 17, 52-63. https://doi.org/10.1016/j.crm. 2017.06.006

Almalki, S. (2016). Integrating quantitative and qualitative data in mixed methods research: Challenges and benefits. Journal of Education and Learning, 5(3), 288-296. https:// doi.org/10.5539/jel.v5n3p288

Antwi, E. K., Boakye-Danquah, J., Owusu, A. B., Loh, S. K., Boafo, Y. A., \& Apronti, P. T. (2015). Community vulnerability assessment index for flood prone savannah agroecological zone: A case study of Wa West District, Ghana. Weather and Climate Extremes, 10, 56-69. https://doi.org/ 10.1016/j.wace.2015.10.008

Arsel, Z. (2017). Asking questions with reflexive focus: A tutorial on designing and conducting interviews. Journal of Consumer Research, 44, 939-948. https://doi.org/10.1093/ jcr/ucx096

Bahinipati, C. S. (2014). Determinants of farm-level adaptation diversity to cyclone and flood: Insights from a farm household-level survey in Eastern India. Water Policy, 17(4), 742-762. https://doi.org/10.2166/wp.2014.121

Coulibaly, J. Y., Gbetibouo, G. A., Kundhlande, G., Sileshi, G. W., \& Beedy, T. L. (2015). Responding to crop failure: Understanding farmers' coping strategies in Southern Malawi. Sustainability, 7(2), 1620-1636.

Dumenu, W. K., \& Obeng, E. A. (2016). Climate change and rural communities in Ghana: Social vulnerability, impacts, adaptations and policy implications. Environmental Science and Policy, 55, 208-217. https://doi.org/10.1016/j. envsci.2015.10.010

Elum, Z. A., Modise, D. M., \& Marr, A. (2017). Farmer's perception of climate change and responsive strategies in three selected provinces of South Africa. Climate Risk Management, 16, 246-257. https://doi.org/10.1016/j.crm.2016. 11.001
Fachrista, I. A., Masyhuri, I., \& Suryantini, A. (2019). Perception of climate change and barriers to adaptation among organic vegetable farmers in Central Java, Indonesia. EurAsian Journal of BioSciences, 13, 1727-1735.

Frischen, J., Meza, I., Rupp, D., Wietler, K., \& Hagenlocher, M. (2020). Drought risk to agricultural systems in Zimbabwe: A spatial analysis of hazard, exposure, and vulnerability. Sustainability, 12, 752. https://doi.org/10.3390/ su12030752

Government of Zimbabwe. (2016). Zimbabwe's National Climate Change Response Strategy. Harare: Ministry of Eniveronment Water and Climate Change.

Government of Zimbabwe. (2017). Zimbabwe's Fifth National Report to the Convention on Biodiversity. Harare: Ministry of Eniveronment Water and Climate Change.

Government of Zimbabwe. (2020). Revision of Zimbabwe's Agro-Ecological Zones. Harare: Zimbabwe National Geospatial and Space Agency (ZINGSA) Report for the Ministry of Higher and Tertiary Education, Innovation, Science and Technology Development.

Jiri, O., \& Mafongoya, P. L. (2018). Managing vulnerability to drought and enhancing smallholder farmers resilience to climate change risks in Zimbabwe. In L. W. Filho (Ed.), Handbook of climate change resilience (pp. 1-17). Berlin: Springer International Publishing AG.

Kangalawe, R. Y. M., Mung, C. G., Mwakaje, A. G., Yanda, P. Z., Kangalawe, R. Y. M., Mung, C. G., \& Mwakaje, A. G. (2017). Climate change and variability impacts on agricultural production and livelihood systems in Western Tanzania. Climate and Development, 9(3), 202-216. https://doi.org/10.1080/17565529.2016.1146119

Kelman, I., Gaillard, J. C., Lewis, J., \& Mercer, J. (2016). Learning from the history of disaster vulnerability and resilience research and practice for climate change. Natural Hazards, 82, 129-143. https://doi.org/10.1007/s11069016-2294-0

Khoza, S., van Niekerk, D., \& Nemakonde, L. D. (2019). Understanding gender dimensions of climate-smart agriculture adoption in disaster-prone smallholder farming communities in Malawi and Zambia. Disaster Prevention and Management: An International Journal, 28(5), 530-547. https://doi.org/10.1108/DPM-10-2018-0347

Kolawole, O. D., Motdholapheko, M. R., Ngwenya, B. N., Thakadu, O., Mmopelwa, G., \& Kgathi, D. L. (2016). Climate variability and rural livelihoods: How households perceive and adapt to climatic shocks in the Okavango Delta, Botswana. Weather, Climate and Society, 8, 131-145. https://doi.org/10.1175/WCAS-D-15-0019.1

Kusakari, Y., Asubonteng, K. O., Jasaw, G. S., Dayour, F., Dzivenu, T., Lolig, V., Donkoh, S. A., Obeng, F. K., Gandaa, B., \& Kranjac-berisavljevic, G. (2014). Farmerperceived effects of climate change on livelihoods in Wa West District, Upper West Region of Ghana. Journal of Disaster Research, 9(4), 516-528.

Kusangaya, S., Warburton, M. L., Garderen, V. A. E., \& Jewitt, G. P. W. (2014). Impacts of climate change on water resources in southern Africa: A review. Journal of Physics and Chemistry of the Earth, 67-69, 47-54. https://doi.org/ 10.1016/j.pce.2013.09.014

Lane, D. C., Munro, E., \& Husemann, E. (2016). Blending systems thinking approaches for organisational analysis: 
Reviewing child protection in England. European Journal of Operational Research, 251(1), 613-623.

Mafongoya, P. L., \& Ajayi, O. C. (Eds.). (2017). Indigenous knowledge systems and climate change management in Africa. Wageningen: The Technical Centre for Agricultural and Rural Cooperation.

Makuvaro, V., Murewi, C. T. F., Dimes, J., \& Chagonda, I. (2018). Are smallholder farmers' perceptions of climate variability and change supported by climate records? A case study of lower Gweru in Semiarid Central Zimbabwe. American Meteorological Society, 10, 35-49. https://doi. org/10.1175/WCAS-D-16-0029.1

Male, T. (2016). Analysing qualitative data. In I. Palaiologou, D. Needham, \& T. Male (Eds.), Doing research in education: Theory and practice (pp. 177-191). SAGE.

Manyani, A., Chagweda, K., Muzenda-mudavanhu, C., \& Chanza, N. (2017). Indigenous-based practices of adapting to climate change: Reflections from Chirumhanzu, Zimbabwe. Journal of Environmental Science, Toxicology and Food Technology, 11(12), 54-66. https://doi.org/10.9790/ 2402-1112015466

Mase, A. S., Gramig, B. M., \& Prokopy, L. S. (2017). Climate change beliefs, risk perceptions, and adaptation behavior among Midwestern U.S. crop farmers. Climate Risk Management, 15, 8-17. https://doi.org/10.1016/j.crm.2016.11. 004

Masud, M. M., Azam, M. N., Mohiuddin, M., Banna, H., Akhtar, R., Alam, A. S. A. F., \& Begum, H. (2017). Adaptation barriers and strategies towards climate change: Challenges in the agricultural sector. Journal of Cleaner Production, 156, 698-706. https://doi.org/10.1016/j.jclepro.2017.04. 060

Masunungure, C., \& Shackleton, S. E. (2018). Exploring longterm livelihood and landscape change in two semi-arid sites in Southern Africa: Drivers and consequences for social-ecological vulnerability. Land, 7(50), 1-23. https:// doi.org/10.3390/land7020050

Mavhura, E. (2017). Applying a systems-thinking approach to community resilience analysis using rural livelihoods: The case of Muzarabani district, Zimbabwe. International Journal of Disaster Risk Reduction, 25, 248-258. https:// doi.org/10.1016/j.ijdrr.2017.09.008

Mavhura, E. (2019). A systems approach for assessing emergency preparedness in underground mines of Zimbabwe. Resources Policy, 62, 1-8. https://doi.org/10.1016/j. resourpol.2019.03.005

Mavhura, E., Manatsa, D., \& Matiashe, M. (2017). Adapting smallholder farming to climate change challenges in Chipinge district. Zimbabwe. Climate Change, 3(12), 903-913.

Mcgrath, C., Palmgren, P. J., \& Liljedahl, M. (2018). Twelve tips for conducting qualitative research interviews. Medical Teacher, 41(9), 1002-1006. https://doi.org/10.1080/ 0142159X.2018.1497149

Mlambo, A. S. (2017). From an industrial powerhouse to a nation of vendors: over two decades of economic decline and deindustrialization in Zimbabwe 1990-2015. Journal of Developing Societies, 33(1), 99-125. https://doi.org/10. 1177/0169796X17694518

Mock, N., Béné, C., Constas, M., \& Frankenberger, T. (2015). Systems Analysis in the Context of Resilience. Resilience
Measurement Technical Working Group. Technical Series No. 6. Rome. Retrieved from http://www.fsincop.net/ fileadmin/user_upload/fsin/docs/resources/FSIN_ TechnicalSeries_6.pdf (Accessed 28 June 2018).

Moyo, M., Mvumi, B. M., Kunzekweguta, M., Mazvimavi, K., Craufurd, P., \& Dorward, P. (2012). Farmer perceptions on climate change and variability in semi-arid Zimbabwe in relation to climatology evidence. African Crop Science Journal, 20, 317-335.

Mubaya, C. P., Njuki, J., Mutsvangwa, E. P., Mugabe, Francid Temba, F., \& Nanja, D. (2012). Climate variability and change or multiple stressors? Farmer perceptions regarding threats to livelihoods in Zimbabwe and Zambia. Journal of Environmental Management, 102, 9-17. https://doi.org/10. 1016/j.jenvman.2012.02.005

Muchabaiwa, L., Chigusiwa, L., Bindu, S., Mudavanhu, V., Damiyano, D., \& Mushanyuri, B. E. (2017). Feasibility and sustainability of community based health insurance in rural areas. Case study of Musana. Zimbabwe. Expert Journal of Finance, 5, 73-85.

Mukwada, G., \& Manatsa, D. (2013). Geospatial and temporal analysis of drought years in Zimbabwe - 1940 to 1999. Geographical Polonica, 86(4), 313-326.

Mutandwa, E., Hanyani-Mlambo, B., \& Manzvera, J. (2019). Exploring the link between climate change perceptions and adaptation strategies among smallholder farmers in Chimanimani district of Zimbabwe. International Journal of Social Economics, 46(7), 850-860. https://doi.org/10. 1108/IJSE-12-2018-0654

Muzari, W., Muvhunzi, S., Soropa, G., \& Kupika, O. L. (2014). Impacts of climate variability and change and farmers' responsiveness in the agricultural sector in Zimbabwe. International Journal of Science and Research, 3(9), 1726-1731.

Muzari, W., Nyamushamba, G. B., \& Soropa, G. (2016). Climate change adaptation in Zimbabwe's agricultural sector. International Journal of Science and Research, 5(1), 1762-1768.

Ndamani, F., \& Watanabe, T. (2015). Farmers' Perceptions about adaptation practices to climate change and barriers to adaptation: A micro-level study in Ghana. Water, 7, 4593-4604. https://doi.org/10.3390/w7094593

Okonya, J. S., Syndikus, K., \& Kroschel, J. (2013). Farmers' perception of and coping strategies to climate change: Evidence From Six Agro-Ecological Zones of Uganda. Journal of Agricultural Science, 5(8), 252-263. https://doi. org/10.5539/jas.v5n8p252

Pachauri, R K, Allen, M. R., Barros, V. R., Broome, J., Cramer, W., Christ, R., \& Dubash, N. K. (2014). Climate Change 2014: Synthesis Report. Contribution of Working Groups I, II and III to the Fifth Assessment Report of the Intergovernmental Panel on Climate Change. (Rejendra K Pachauri \& L. Meyer, Eds.). Geneva: Intergovernmental Panel on Climate Change.

Pasimeni, M. R., Valente, D., Zurlini, G., \& Petrosillo, I. (2019). The interplay between urban mitigation and adaptation strategies to face climate change in two European countries. Environmental Science and Policy, 95, 20-27. https:// doi.org/10.1016/j.envsci.2019.02.002

Rankoana, S. A. (2016). Perceptions of climate change and the potential for adaptation in a rural community in Limpopo 
Province. South Africa. Sustainability MDPI, 8, 672. https://doi.org/10.3390/su8080672

Rojas-Downing, M. M., Nejadhashemi, A. P., Harrigan, T., \& Woznicki, S. A. (2017). Climate change and livestock: Impacts, adaptation, and mitigation. Climate Risk Management, 16, 145-163. https://doi.org/10.1016/j.crm.2017. 02.001

Rurinda, J., Van Wijk, M. T., Mapfumo, P., Descheemaeker, K., Supit, I., \& Giller, K. E. (2015). Climate change and maize yield in southern Africa: What can farm management do? Global Change Biology, 21, 4588-4601. https://doi.org/10. $1111 /$ gcb. 13061

Sango, I., \& Nhamo, G. (2015). Climate change trends and environmental impacts in the Makonde Communal Lands, Zimbabwe. South African Journal of Science, 111(7/8), 2014-0266.

Spear, D., Haimbili, E., Angula, M., Baudoin, M.-A., Hegga, S., Zaroug, M., \& Okeyo, A. (2018). Vulnerability and Adaptation to Climate Change in the Semi-Arid Regions of Southern Africa.

Tessema, I., \& Simane, B. (2020). Smallholder Farmers' perception and adaptation to climate variability and change in Fincha sub-basin of the Upper Blue Nile River Basin of Ethiopia. GeoJournal. https://doi.org/10.1007/s10708020-10159-7

Tortajada, C., Kastner, M. J., Buurman, J., \& Biswas, A. K. (2017). The California drought: Coping responses and resilience building. Environmental Science and Policy, 78, 97-113. https://doi.org/10.1016/j.envsci.2017.09.012

Tripathi, A., \& Mishra, A. K. (2017). Knowledge and passive adaptation to climate change: An example from Indian farmers. Climate Risk Management, 16, 195-207. https:// doi.org/10.1016/j.crm.2016.11.002

UNICEF. (2015). Zimbabwe Poverty Atlas: Small Area Poverty Estimation. Statistics for Poverty Eradicationn. Harare: UNICEF, World Bank and Zimbabwe National Statistics Agency.

Valencia, E. (2020). Acquiescence, instructor's gender bias and validity of student evaluation of teaching. Assessment \&
Evaluation in Higher Education, 45(4), 483-495. https:// doi.org/10.1080/02602938.2019.1666085

Wood, S. A., Jina, A. S., Jain, M., Kristjanson, P., \& Defries, R. S. (2014). Smallholder farmer cropping decisions related to climate variability across multiple regions. Global Environmental Change, 25, 163-172. https://doi.org/10.1016/j. gloenvcha.2013.12.011

World Bank. (2019). Zimbabwe: Agriculture Sector Disaster Risk Assessment. Washington: World Bank.

Yadav, S. S., \& Lal, R. (2018). Vulnerability of women to climate change in arid and semi-arid regions: The case of India and South Asia. Journal of Arid Environments, 149, 4-17. https://doi.org/10.1016/j.jaridenv.2017.08.001

Yayeh, D. A., \& Leal, W. F. (2017). Farmers' perceptions of climate variability and its adverse impacts on crop and livestock production in Ethiopia. Journal of Arid Environments, 140, 20-28. https://doi.org/10.1016/j.jaridenv. 2017.01.007

Yin, R. K. (2009). Case study researchL Design and methods (4th ed.). Thousand Oaks: Sage.

Zamasiya, B., Nyikahadzoi, K., \& Mukamuri, B. B. (2017). Factors influencing smallholder farmers' behavioural intention towards adaptation to climate change in transitional climatic zones: A case study of Hwedza District in Zimbabwe. Journal of Environmental Management, 198, 233-239. https://doi.org/10.1016/j.jenvman.2017.04.073

ZIMSTAT. (2015). Zimbabwe Poverty Atlas. Zimbabwe National Statistical Agency (ZIMSTAT), Harare. http:// www.nada.zimstat.co.zw/ (Accessed 19 November, 2019)

ZIMSTAT. (2017). Inter-Censal Demographic Survey 2017. Zimbabwe National Statistical Agency (ZIMSTAT), Harare. http://www.nada.zimstat.co.zw/ (Accessed 21 October 2019)

ZIMSTAT. (2019). Zimbabwe Smallholder Agricultural Productivity. Harare: Zimbabwe National Statistics Agency.

Publisher's Note Springer Nature remains neutral with regard to jurisdictional claims in published maps and institutional affiliations. 